\title{
The Error Pattern of Students with Mathematics Learning Disabilities in the Inclusive School on Fractions Learning
}

\author{
Trisno Ikhwanudin \\ Postgraduate Program, Mathematics Education Department, \\ Universitas Pendidikan Indonesia, Bandung, Indonesia \\ Sufyani Prabawanto and Wahyudin \\ Mathematics Education Department, \\ Universitas Pendidikan Indonesia, Bandung, Indonesia
}

\begin{abstract}
This study examines the error pattern of students with mathematics learning disabilities when they learn fractions. This research uses a qualitative approach. The respondents are 23 students of the $7^{\text {th }}$ graders in the inclusive school. The data are collected through student tests, class observations, and teacher interviews. The grounded theory with the constant comparison is conducted to the data analysis. There are four similar error patterns: (1) a lack of understanding of fraction representation; (2) a lack of understanding of fraction comparisons; (3) a mistake in applying the common denominator approach to the fraction addition operation; (4) a mistake in applying the procedure of fraction multiplication operation. The results of this study can be used by the teachers as a guideline when teaching fractions to students in inclusive schools.
\end{abstract}

Keywords: Fraction Learning, Inclusive Education, Pattern Error Analysis, Mathematics Learning Disabilities.

\section{Introduction}

In Indonesia, schools with the potential to receive a wide variety of students from excel to those with mathematics learning disabilities (MLD) are inclusive schools. In the inclusive schools, each child meets his or her specific needs, students can be optimally served by various modifications and adjustments, from the curriculum, facilities, educators, and the learning system to the scoring system.

Some literature discussed learning mathematics in an inclusive setting. For example, NCTM (2000) stated that all students must have opportunities to study 
and support to learn mathematics; regardless of their trait, backgrounds, or physical impairment. Furthermore, the Equity Principle stated that equity does not mean that each student should receive the same instruction; however, it depends on the need of all students (NCTM, 2000).

Researchers stated that students understand mathematical ideas and build them in a variety of ways, depending on the experience of life and their unique mathematics learning; understanding and appreciation of the teachers to the difference of these students will increase the confidence of students in learning mathematics and support mathematical understanding of students more deeply (Castellon et al., 2011; Schifter, 2005; Zevenbergen et al., 2004).

The equity principle is an excellent idea in the mathematics classroom. However, the research that explores mathematics learning in inclusive settings is very limited, based on research findings, between 2000 and 2013 there were only five studies discussing mathematics learning in inclusive settings (McKenna, Shin \& Ciullo, 2015).

Therefore, in this study, the research problems are focused on how the error pattern of MLD students in an inclusive school when they learn fractions. The results of this study are expected to add to the discourse of educational scholarship, especially on the teaching and learning mathematics in an inclusive setting for students with MLD.

\section{Literature Review}

The definition of the fraction is a symbol that represents the results of two numbers $\frac{a}{b}$, with b not equal to zero (Clarke et al., 2010). In the preliminary study, inclusive school teachers state that fractions were one of the topics that difficult to teach. The teachers' opinion is in line with the finding of Lewis and Fisher (2016), they stated that the study of fractions requires high-level thinking ability or complex ability; they also stated that the study of MLD student needs research on a topic that demands complex ability. Furthermore, understanding fractions are very crucial for the students in learning mathematics. Fractions are the foundation for the study of algebra and mathematics at a higher level (Bailey et al., 2012; Torbeyns et al., 2014; Shin \& Bryant, 2016).

In general case, based on the research of Coetzeea and Mammen (2017), the difficulty with fractions is still felt by students until they enroll in the science and engineering diploma program. They also stated that students struggle with fractions in the form of a word problem. In the MLD students case, researchers stated that students with MLD still feel the difficulties in fractions learning until they are in grade 8 (Mazzocco et al., 2013). Another research showed that MLD students use false traditional algorithms in fractions learning (Newton et al., 2014).

Geary (2004) stated that MLD students have an average IQ with standardized test scores are below the 20th or 25th percentiles. Piazza et al. (2010) explained students with MLD was students that slower and often make mistakes in the 
processing of representations of numbers, for example, the symbol of the numbers "3" and the matching representation " $\diamond$ ". Mazzocco et al. (2011) stated that students with MLD make an error in compare and estimate numbers. Geary et al. (2004) found that students with MLD make a mistake in calculating arithmetic. The other researchers noted that MLD students make a mistake in solving the problem of a very easy number; for example, $4 \times 5=20$ (Mazzocco et al., 2008).

Lewis (2014) stated that students with MLD have different methods of thinking in understanding fractions. She also suggested a younger research subject. i.e., elementary or junior high school students. Lewis (2016a) stated that MLD students have obstacles in fractions comparison, i.e. fractions comparisons with the same denominator or fractions comparisons that involve a fraction $\frac{1}{2}$. Hunt et al. (2016) stated that MLD students have difficulty in grasping the part-whole model of fractions.

\section{Methods}

The method section describes the research methods used including research design, research subjects, research procedure, and data analysis.

\section{Research Design}

This research uses a qualitative approach, with descriptive method (Gall, Gall, \& Borg, 2010). The data are collected through student tests, class observations, and teacher interviews.

\section{Research Subjects}

The study is conducted in the Inclusive School in the West Java Province, Indonesia. The subjects of this study are 23 students of the $7^{\text {th }}$ graders in the inclusive classroom. Students are given the tests instrument, then the students' answer is analyzed. From the result of student test, observation, and teacher interview, we then identify three students who are suspected of having MLD and analyze the error pattern of students with MLD on fractions learning.

\section{Research Procedures}

The procedure of this study is made by the following steps:

Conducting tests

The test is performed with the instrument that has been compiled and validated by the experts. The complete test items are as follows:

Table 1: The test instruments

\begin{tabular}{cc}
\hline No & Problems \\
\hline 1 & Draw the following fractions: $\frac{1}{2}$ and $\frac{2}{5}$ with two different ways.
\end{tabular}


2 Check which fraction images are larger:
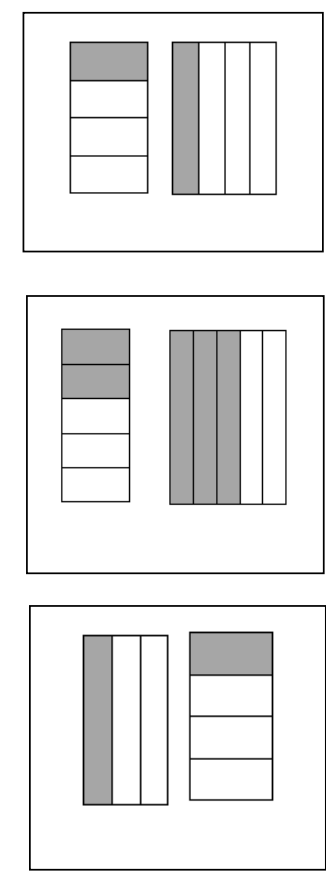

3

a. Explain which one is larger: $\frac{1}{2}$ or $\frac{2}{3}$

b. Explain which one is larger: $\frac{2}{3}$ or $\frac{3}{4}$

$4 \quad$ Write down your way to find two fractions which are equal $\frac{1}{2}$ ?

5 Complete the following problems with the steps.
a. $\frac{1}{3}+\frac{1}{3}=$
b. $\frac{1}{3}+\frac{1}{2}=$

$6 \quad$ Complete the following problems with the steps.
a. $\frac{4}{5} \times \frac{1}{3}=$
b. $\frac{9}{4} \div \frac{3}{5}=$

$7 \quad$ Susi ran $\frac{2}{5} \mathrm{~km}$ on Monday. On Tuesday, Susi ran $\frac{3}{7} \mathrm{~km}$. Explain how many kilometers $(\mathrm{km})$ Susi ran on both days? 
The result of the test is as follow:

Table 2: The test result

\begin{tabular}{ccccccccc}
\hline Students & Q1 & Q2 & Q3 & Q4 & Q5 & Q6 & Q7 & Score \\
\hline 1 & 10 & 10 & 10 & 10 & 10 & 10 & 10 & 100 \\
\hline 2 & 5 & 0 & 10 & 10 & 5 & 5 & 10 & 64.29 \\
\hline 3 & 5 & 7.5 & 5 & 0 & 0 & 0 & 0 & 25.00 \\
\hline 4 & 5 & 5 & 0 & 0 & 10 & 10 & 10 & 57.14 \\
\hline 5 & 10 & 7.5 & 10 & 5 & 5 & 10 & 0 & 67.86 \\
\hline 6 & 10 & 0 & 10 & 0 & 10 & 10 & 10 & 71.43 \\
\hline 7 & 5 & 10 & 10 & 10 & 10 & 10 & 10 & 92.86 \\
\hline 8 & 10 & 0 & 10 & 10 & 10 & 10 & 10 & 85.71 \\
\hline 9 & 5 & 10 & 10 & 10 & 10 & 10 & 10 & 92.86 \\
\hline 10 & 10 & 0 & 10 & 5 & 7.5 & 10 & 10 & 75.00 \\
\hline 11 & 5 & 10 & 10 & 10 & 10 & 10 & 10 & 92.86 \\
\hline 12 & 10 & 7.5 & 10 & 10 & 10 & 10 & 10 & 96.43 \\
\hline 13 & 5 & 10 & 10 & 10 & 10 & 10 & 10 & 92.86 \\
\hline 14 & 10 & 7.5 & 5 & 10 & 5 & 5 & 10 & 75.00 \\
\hline 15 & 5 & 0 & 10 & 10 & 0 & 0 & 0 & 35.71 \\
\hline 16 & 5 & 0 & 10 & 10 & 5 & 10 & 10 & 71.43 \\
\hline 17 & 7.5 & 0 & 10 & 10 & 0 & 0 & 0 & 39.29 \\
\hline 18 & 0 & 0 & 0 & 0 & 0 & 0 & 0 & 0.00 \\
\hline 19 & 5 & 0 & 10 & 10 & 5 & 5 & 10 & 64.29 \\
\hline 20 & 10 & 0 & 0 & 0 & 10 & 0 & 10 & 42.86 \\
\hline 21 & 5 & 0 & 0 & 10 & 5 & 10 & 10 & 57.14 \\
\hline 22 & 2.5 & 0 & 0 & 10 & 5 & 0 & 0 & 25.00 \\
\hline 23 & 5 & 0 & 5 & 0 & 0 & 0 & 0 & 14.29 \\
\hline & & & & & & & &
\end{tabular}

Based on the result of the data analysis, the $25^{\text {th }}$ percentile (first quartile) of the score is 66.9. Score 66.9 indicates the upper bound of $25 \%$ of the lowest score. According to Geary (2004), one way to determine the MLD student is the students whose test results are below the $25^{\text {th }}$ percentile. By paying attention to scores that are below the $25^{\text {th }}$ percentile, 11 students are suspected of experiencing MLD. The students are respectively number $2,3,4,15,17,18,19$, $20,21,22$, and 23 .

Teacher Interview and Class Observation

According to Lewis (2016b), to determine students with MLD, test results can be strengthened with the results of observation and interviews. The results of observations and interviews are needed to reveal that there is no influence of environmental or social factors on students' inability in mathematics.

Based on the teacher's interview and class observation of 11 students that suspected of experiencing MLD; the following results are obtained:

- Students number 2,4, and 20 get the score $64.3,57.14$, and 42.86 respectively. These scores are below the $25^{\text {th }}$ percentile, which is 66.9 . However, based on interviews with the teacher, they do not experience significant difficulties in learning mathematics. So, student number 2, 4, and 20 are not concluded with having MLD. 
- Student number 3, 21, 22, and 23 get the score 25, 57.14, 25, 14.29 respectively. These scores are below the $25^{\text {th }}$ percentile, which is 66.9. However, based on the observation, the students are less serious in doing the test; this can be seen from some questions that do not answer by the student. So the researchers and the teacher conclude that the results of students answer are not sufficient to be analyzed, and remove students from the list of prospective students who experienced MLD.

- The student number 15, 17, and 19 get the score 35.71, 39.29, and 64.29 respectively. These scores are below the $25^{\text {th }}$ percentile, which is 66.9. Based on interviews with the teacher, they have difficulties in learning mathematics. Therefore, they are recorded as MLD students.

- The student number 18 cannot answer the question. Accord teacher interview, the student is included in the category of special needs student with slow learner criteria. The student number 18 does not include in the MLD category because the MLD criteria used in this study is a student with average intelligence or above.

Based on the teacher interview and class observation, the researchers and the teacher agree that there are only three students who experienced MLD. Students with MLD are respectively number 15, 17, and 19.

\section{Data Analysis}

The grounded theory with coding and constant comparison technique is used for data analysis. The grounded theory procedures as presented by Gall, Gall, and Borg (2010) through the four steps. The first step is data collection; the second step is a division of data into several segments. The third step is defining specific categories that reflect both the conceptual and structural elements of the data, and the fourth step is the coding of each segment for each appropriate category in each segment.

\section{Findings}

After examining three students with MLD, the analysis of the error pattern of MLD student is conducted. We call the three MLD students with student A, B, and $\mathrm{C}$.

The error pattern of student $A$

In question number 1 , student $\mathrm{A}$ gives the following answer:

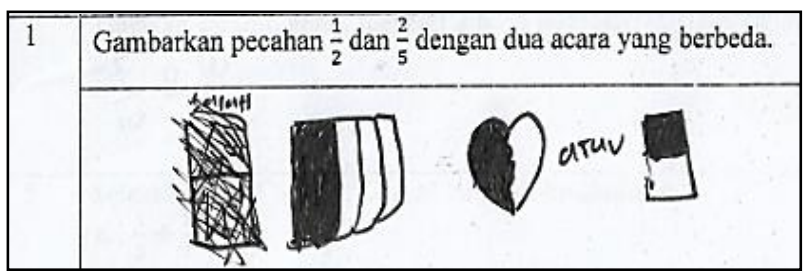

Figure 1: Student $A$ answer for item \#1

In figure 1 , student $\mathrm{A}$ describes fractions $\frac{1}{2}$ and $\frac{2}{5}$ in two different ways. He draws a representation of $\frac{1}{2}$ with two different ways, that are the heart and the rectangle images. While at the fraction $\frac{2}{5}$, he draws a representation which is like a 
rectangle. From the answer to question 1, it appears that he does not well understand the fraction representation.

In question 2, student A gives the following answers:

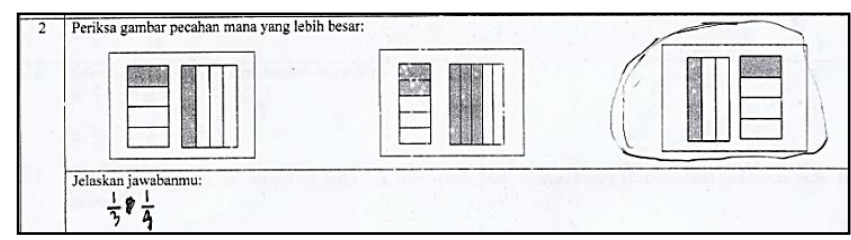

Figure 2: Student $\mathrm{A}$ answer for item \#2

In figure 2, student A checks which fractions representation images are larger. There are three different images of the problem. He only writes $\frac{1}{3}$ and $\frac{1}{4}$, without writing another explanation. From the answer to question 2, it appears that student $\mathrm{A}$ does not understand the representation and comparison of fractions.

In question 3, student A gives the following answers:

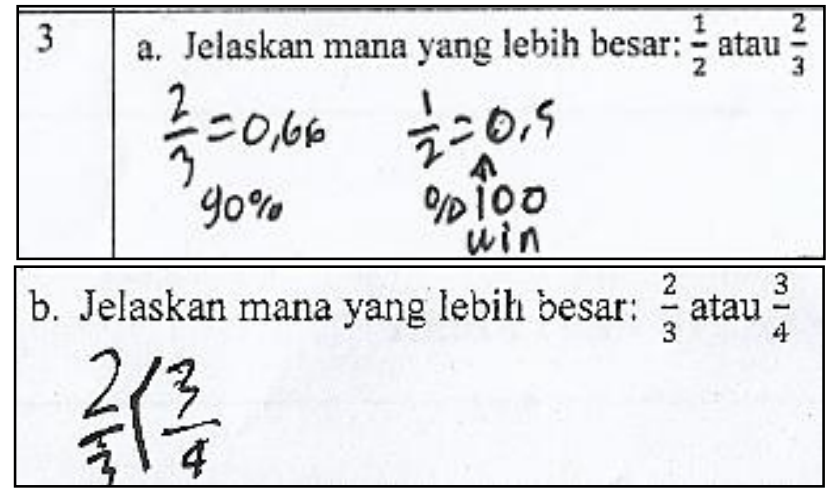

Figure 3: Student A answer for item \#3

In part a, student A explains which fractions are larger between $\frac{1}{2}$ and $\frac{2}{3}$. He uses decimal strategy to explain larger fractions. He changes fraction $\frac{2}{3}$ to 0.66 and $\frac{1}{2}$ to 0.5 . However, he notes that $90 \%$ and $100 \%$ win, without giving any other details.

In part $b$, student $A$ explains which fractions are larger between $\frac{2}{3}$ and $\frac{3}{4}$. He gives the correct answer, that is $\frac{2}{3}<\frac{3}{4}$. However, he does not explain how the answer is obtained. From the answer to question 3, it appears that student A does not understand the fraction comparisons.

In question 4, student $\mathrm{A}$ gives the following answer:

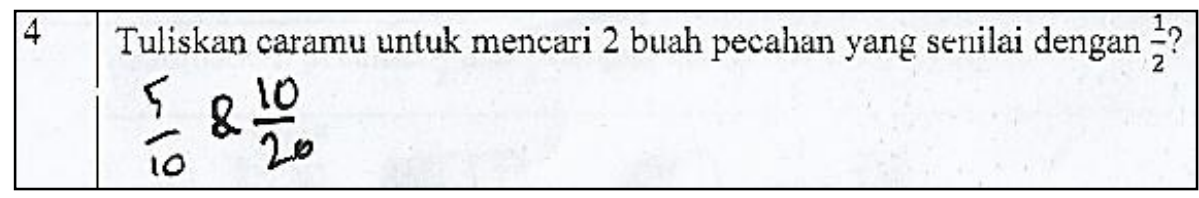

Figure 4: Student A answer for item \#4 
In figure 4 , student $\mathrm{A}$ writes strategies to find two fractions that equivalent to $\frac{1}{2}$. He gives the correct answer, that is $\frac{5}{10}$ and $\frac{10}{20}$. He multiplies the numerator and denominator of fractions $\frac{1}{2}$ by 5 . From the answer of number 4 , it appears that student A already understands the topic of fractions equivalent.

In question 5, student A gives the following answer:

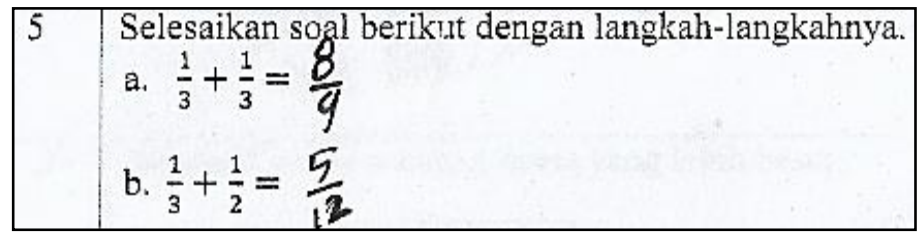

Figure 5: Student $A$ answer for item \#5

In figure 5, student A completes two questions about fractions addition. In the first question, he solves the problem $\frac{1}{3}+\frac{1}{3}=\cdots$. This problem aims to check students' understanding of fractions addition with the same denominator. Student A's answer is $\frac{1}{3}+\frac{1}{3}=\frac{8}{9}$. His thinking can be analyzed as follows: $\frac{1}{3}+\frac{1}{3}=\frac{(1+3)}{(3 \times 3)}+\frac{(1+3)}{(3 \times 3)}=\frac{4}{9}+\frac{4}{9}=\frac{8}{9}$.

Student A knows the common denominator strategy on fraction addition. So, when the student sees the problem $\frac{1}{3}+\frac{1}{3}=\cdots$, he applies the common denominator strategy by changing 3 to 9 . He does not understand that the denominator is the same, that is 3 . He adds the numerator by 3 , not multiplying it, as follows: $\frac{1}{3}+\frac{1}{3}=\frac{(1+3)}{(3 \times 3)}+\frac{(1+3)}{(3 \times 3)}=\frac{4}{9}+\frac{4}{9}=\frac{8}{9}$. He knows that if the denominator is multiplied by 3 , then the numerator is also multiplied by 3 . But, the numerator is added by 3 instead of multiply by 3 . He mistakenly applies the procedures.

In the second question, he solves the problem $\frac{1}{3}+\frac{1}{2}=\cdots$. This problem aims to check students' understanding of fractions addition with different denominators. He answers: $\frac{1}{3}+\frac{1}{2}=\frac{5}{12}$. His thinking can be analyzed as follows: $\frac{1}{3}+\frac{1}{2}=\frac{(1 \times 2)}{(3 \times 2)}+$ $\frac{(1 \times 3)}{(2 \times 3)}=\frac{2}{6}+\frac{3}{6}=\frac{2+3}{6+6}=\frac{5}{12}$. He knows the common denominator strategy on the fraction addition operation. Therefore, when the student sees the problem $\frac{1}{3}+\frac{1}{2}=\cdots$, he performs the common denominator strategy by changing 3 to 6 and 2 to 6 .

There are interesting things done by student $\mathrm{A}$. He adds not only the numerator but also the denominator, as follows: $\frac{1}{3}+\frac{1}{2}=\frac{2}{6}+\frac{3}{6}=\frac{2+3}{6+6}=\frac{5}{12}$. Thus, Student A knows the common denominator procedure on the fraction addition operation. However, in the process, he adds not only the numerator but also the denominator. He mistakenly applies the strategy that he already knows. 
In question 6, student $\mathrm{A}$ gives the following answer:

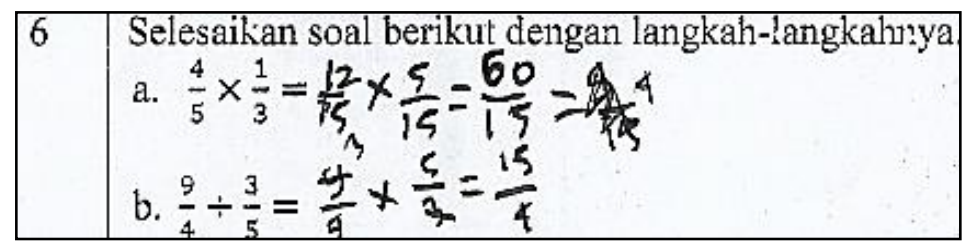

Figure 6: Student A answer for item \#6

In figure 6, he solves two problems of fractions multiplication. In the first question, he solves the problem $\frac{4}{5} \times \frac{1}{3}=\cdots$. This problem aims to check students' understanding of fractions multiplication. His answer is $\frac{4}{5} \times \frac{1}{3}=\frac{12}{15} \times \frac{5}{15}=\frac{60}{15}=4$. There is an interesting point, he applies the common denominator strategy to the fraction multiplication. Therefore, when he sees the problem $\frac{4}{5} \times \frac{1}{3}=\cdots$, he applies the common denominator strategy in the first term by changing the 5 to 15 and in the second term by changing 3 to 15 . Furthermore, he only multiplies the numerator, as follow $\frac{12}{15} \times \frac{5}{15}=\frac{60}{15}$. The interesting thing is he applies the fraction addition procedure to the fraction multiplication operations.

In the second question, he solves the problem $\frac{9}{4} \div \frac{3}{5}=\cdots$. This problem aims to check students' understanding of fraction division. He gives the correct answer as follows: $\frac{9}{4} \div \frac{3}{5}=\frac{9}{4} \times \frac{5}{3}=\frac{3}{4} \times \frac{5}{1}=\frac{15}{4}$. He uses multiplication algorithms with the inverse of the second term or inverts multiply algorithm (Zembat, 2015).

In item number 7 , student $\mathrm{A}$ does not provide the correct answers. Answer sheets were still emptied as follow:

\begin{tabular}{|l|l|}
\hline 7 & $\begin{array}{l}\text { Susi berlari } \frac{2}{5} \mathrm{~km} \text { pada hari senin. Pada hari sclasa, Susi berlari } \frac{3}{7} \mathrm{~km} \text {. Jelaskan berapa kilometer }(\mathrm{km}) \text { Susi berlari pada kedua hari } \\
\text { tersebut? }\end{array}$ \\
\hline
\end{tabular}

Figure 7: Student A answer for item \#7

From figure 7, it appears that student $\mathrm{A}$ is less able to understand and to model a fraction word problem.

The following table is the error pattern of student A:

Table 5: The error pattern of student A

\begin{tabular}{cl}
\hline No & The Error Pattern of Student A \\
\hline 1 & A lack of understanding of fraction representations \\
\hline 2 & A lack of understanding of fraction comparisons \\
\hline 3 & $\begin{array}{l}\text { A mistake in applying the common denominator procedure to the fraction addition } \\
\text { operation }\end{array}$ \\
\hline 4 & Applying the common denominator procedure to fraction multiplication operations \\
\hline 5 & Could not solve the word problem of fractions \\
\hline
\end{tabular}


The error pattern of student $B$

In question 1, student $B$ gives the following answer:

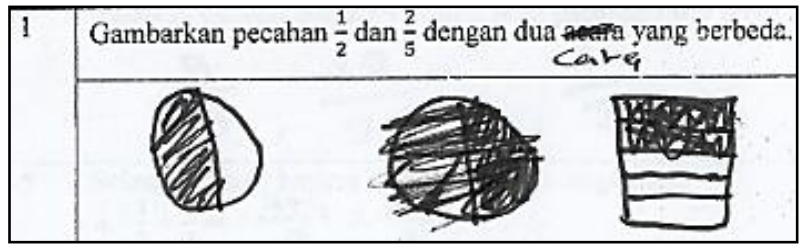

Figure 8: Student B answer for item \#1

In figure 8 , student $B$ describes fractions $\frac{1}{2}$ and $\frac{2}{5}$ in two different ways. He draws a representation of $\frac{1}{2}$ with a circular model divided into two parts, with one part shaded. For fraction $\frac{2}{5}$, he draws a representation that was a kind of rectangle, which divided into five parts, with two parts shaded. From the answer to number 1, it appears that he did not well understand the fraction representation.

In question 2, student B gives the following answer:

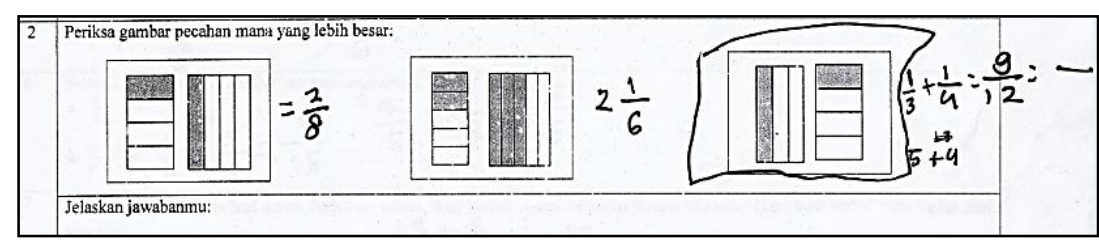

Figure 9: Student B answer for item \#2

In figure 9, student B checks which fractions representation images are larger. There are three different images of the problem. He does not provide sufficient explanation for analysis, but something is interesting, that is about the note on the right side: $\frac{1}{3}+\frac{1}{4}=\frac{9}{12}$. His understanding of the fraction addition operation is similar to student A's understanding. Consider his thinking: $\frac{1}{3}+\frac{1}{4}=\frac{(1+4)}{(3 \times 4)}+$ $\frac{(1+3)}{(4 \times 3)}=\frac{5}{12}+\frac{4}{12}=\frac{9}{12}$ (noted that student B's writing: $5+4$ below the equation $\left.\frac{1}{3}+\frac{1}{4}=\frac{9}{12}\right)$. As student $\mathrm{A}$, student $\mathrm{B}$ has known the procedure of common denominator on fraction addition operation. So, when he sees the question $\frac{1}{3}+$ $\frac{1}{4}=\ldots$, he performs the common denominator procedure by converting 3 to 12 in the first term and 4 to 12 in the second term.

There is another interesting thing done by student B. He adds the first numerator with 4 and the second numerator with 3 instead of multiplying it, the illustration is as follows: $\frac{1}{3}+\frac{1}{4}=\frac{(1+4)}{(3 \times 4)}+\frac{(1+3)}{(4 \times 3)}=\frac{5}{12}+\frac{4}{12}=\frac{9}{12}$. In the first term, he knows that if the denominator multiplied by four, then the numerator is also multiplied by four. However, the numerator is added by four, not multiplied by four. He mistakenly applies the procedure. From the answer of question 2, student $\mathrm{B}$ does not understand fraction representation and comparison. He also 
makes a mistake in applying the common denominator procedure to the operation of addition of fractions.

In question 3, student $B$ gives the following answers:

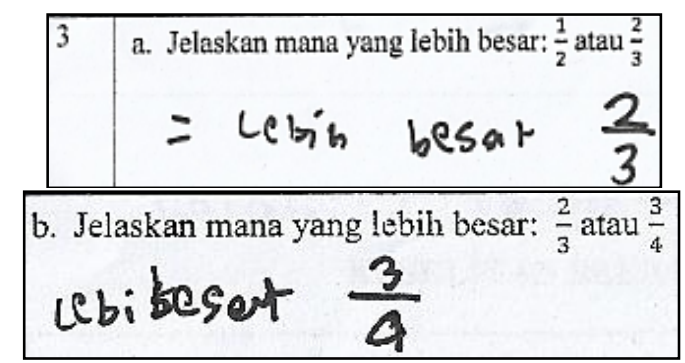

Figure 10: Student $B$ answer for item \#3

In part a, student $B$ explains which fractions are larger between $\frac{1}{2}$ and $\frac{2}{3}$. He gives the correct answer, that is $\frac{2}{3}$ is larger, without giving other information. In part $b$, student B explains which fractions are larger between $\frac{2}{3}$ and $\frac{3}{4}$. He gives the correct answer, that is $\frac{3}{4}$ is larger. However, he does not explain how the answer is obtained. From the answer to question number 3, it appears that student B less understand fraction comparisons.

In question number 4 , student $B$ gives the following answer:

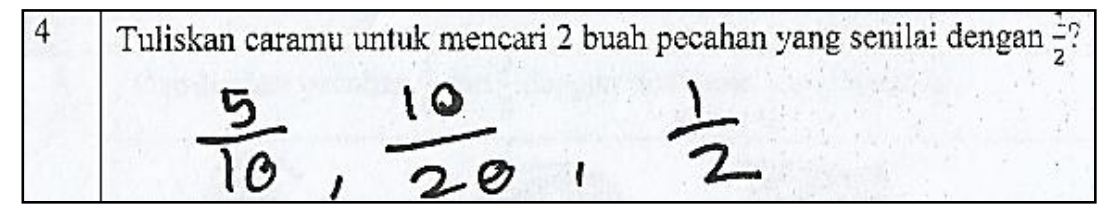

Figure 11: Student $B$ answer for item \#4

In figure 11, student B writes strategies to find two fractions that equivalent to $\frac{1}{2}$. $\mathrm{He}$ has been able to provide the correct answer, which is $\frac{5}{10}$ and $\frac{10}{20}$. He multiplies the numerator and denominator of fractions $\frac{1}{2}$ by 5 . From the answer to question 4 , it appears that student B already understands the topic about the fraction equivalent.

In question number 5, student $B$ gives the following answer:

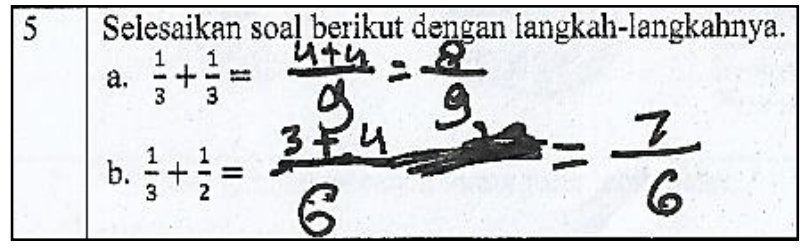

Figure 12: Student $B$ answer for item \#5

In figure 12, student B solves two questions about fractions addition. In part a, he solves $\frac{1}{3}+\frac{1}{3}=\cdots$. This problem aims to check students' understanding of the 
addition operation with the same denominator. His answer is $\frac{1}{3}+\frac{1}{3}=\frac{8}{9}$. His thinking can be analyzed as follows: $\frac{1}{3}+\frac{1}{3}=\frac{(1+3)}{(3 \times 3)}+\frac{(1+3)}{(3 \times 3)}=\frac{4}{9}+\frac{4}{9}=\frac{8}{9}$. This understanding is the same as the understanding of student $A$, though by different writing (student A goes straight to the answer $\frac{8}{9}$ ).

Similarly, with student A, student B knows the procedure of common denominator on a fraction addition operation. Thus, when he sees the question of $\frac{1}{3}+\frac{1}{3}=\cdots$, he performs the common denominator procedure by converting 3 to 9 in each term. However, he does not understand that the denominator of the problem is the same, that is 3 . Furthermore, he adds the numerator by three, not multiplying it, as the following illustration: $\frac{1}{3}+\frac{1}{3}=\frac{(1+3)}{(3 \times 3)}+\frac{(1+3)}{(3 \times 3)}=\frac{4}{9}+\frac{4}{9}$. He knows that if the denominator is multiplied by three, then the numerator is also multiplied by three. However, the numerator is added by three instead of multiply by three. He mistakenly applies the fraction addition procedure.

In part $b$, he solves $\frac{1}{3}+\frac{1}{2}=\cdots$. His answer is $\frac{1}{3}+\frac{1}{2}=\frac{3+4}{6}=\frac{7}{6}$. His way of thinking can be analyzed as follows: $\frac{1}{3}+\frac{1}{2}=\frac{(1+2)}{(3 \times 2)}+\frac{(1+3)}{(2 \times 3)}=\frac{3+4}{6}=\frac{7}{6}$. He knows the procedure of common denominator on the fraction addition operation. So, when he sees the problem $\frac{1}{3}+\frac{1}{2}=\cdots$, he performs the common denominator procedure by converting 3 to 6 in the first term and 2 to 6 in the second term.

The same as the previous problem (and this also happens to student A), there are other interesting things done by student $\mathrm{B}$. He adds 1 (numerator) with 2 in the first term, and added 1 (numerator) with 3 in the second term instead of multiplying it, as the following illustration: $\frac{1}{3}+\frac{1}{2}=\frac{(1+2)}{(3 \times 2)}+\frac{(1+3)}{(2 \times 3)}=\frac{3+4}{6}$. Thus, he knows the procedure of common denominator, that is the denominator and the numerator must be multiplied by 2 . However, the numerator is added by 2 instead of multiplied by 2 . From the answer of number 5, it appears that student $\mathrm{B}$ is doing wrong in applying the common denominator procedure of the addition of fractions.

In question 6, student B gives the following answers:

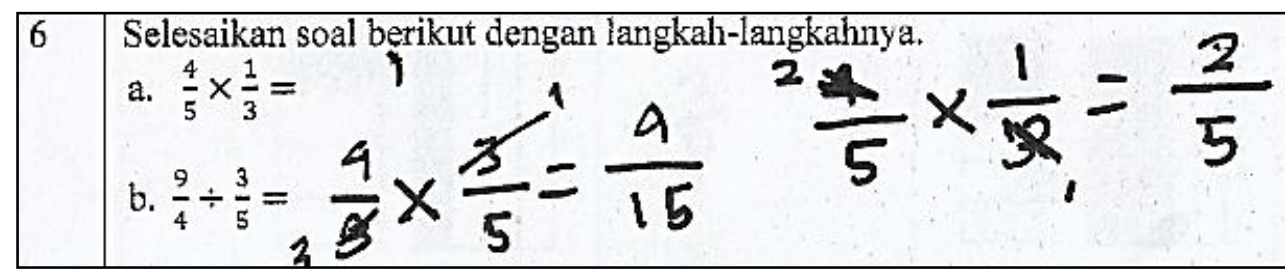

Figure 13: Student $B$ answer for item \#6

In figure 13, student B solves two problems of fractions multiplication. In part a, he solves $\frac{4}{5} \times \frac{1}{3}=\cdots$. His answer is $\frac{4}{5} \times \frac{1}{3}=\frac{2}{5} \times \frac{1}{1}=\frac{2}{5}$. Note that student $B$ miscalculated by simplifying 4 (the numerator in the first term) and 3 (the 
denominator in the second term), 4 being 2 and 3 is 1 . This simplification is one form of student B miscalculation.

In part $b$, he solves $\frac{9}{4} \div \frac{3}{5}=\cdots$. He appears to have learned the strategy of a fractions division operation. However, surprisingly, he uses multiplying the inverse strategy, but the reverse is not the second term, but the first term. Consider his thinking: $\frac{9}{4} \div \frac{3}{5}=\frac{4}{9} \times \frac{3}{5}=\frac{4}{15}$. So, the answer is reversed, it should be $\frac{15}{4}$.

In question 7, student B gave the following answers:

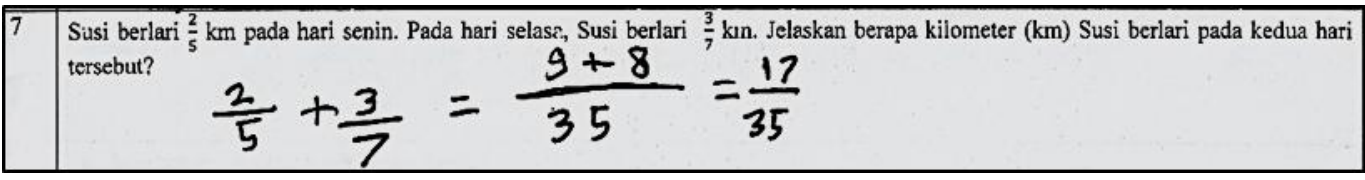

Figure 14: Student $B$ answer for item \#7

In figure 14, student B solves a fractions word problem. The problem is as follows: "Susi ran $\frac{2}{5} \mathrm{~km}$ on Monday. On Tuesday, Susi ran $\frac{3}{7} \mathrm{~km}$. Explain how many kilometers $(\mathrm{km})$ Susi ran on both days? ". This problem aims to check the students' understanding of fractions in the word problem. In this case, he has been able to model the word problem into a mathematical equation, which is the operation of fractions addition. His answer is as follows: $\frac{2}{5}+\frac{3}{7}=\frac{9+8}{35}=\frac{17}{35}$. The student's way of thinking can be analyzed as follows: $\frac{2}{5}+\frac{3}{7}=\frac{(2+7)}{(5 \times 7)}+\frac{(3+5)}{(7 \times 5)}=$ $\frac{9+8}{35}=\frac{17}{35}$.

Student B knows the common denominator strategy on fraction addition. When he sees the problem: $\frac{2}{5}+\frac{3}{7}=\cdots$, he performs the common denominator procedure by converting 5 to 35 in the first term and 7 to 35 in the second term. Surprisingly, he adds 2 (numerator) with 7 in the first term and 3 (numerator) with 5 in the second term, instead of multiplying it, as follows: $\frac{2}{5}+\frac{3}{7}=\frac{(2+7)}{(5 \times 7)}+$ $\frac{(3+5)}{(7 \times 5)}=\frac{9+8}{35}=\frac{17}{35}$. He knows the procedure that is if the denominator is multiplied by 7 , then the numerator is also multiplied by 7 . However, the numerator is added by 7 , not multiplied by 7 . He mistakenly applies the procedures that already knew.

The following table is the summary of the error pattern of student B:

Table 6: The error pattern of student B

\begin{tabular}{ll}
\hline No & The Error Pattern of Student B \\
\hline 1 & A lack of understanding of fraction representations \\
\hline 2 & A lack of understanding of fraction comparisons \\
\hline
\end{tabular}




\begin{tabular}{ll}
\hline 3 & $\begin{array}{l}\text { A Mistake in applying the common denominator procedure to the fraction } \\
\text { addition operation }\end{array}$ \\
\hline 4 & A miscalculation in simplifying numbers on fraction multiplication \\
\hline 5 & In the fraction division operation, the first term is reversed, not the second term
\end{tabular}

The error pattern of student $C$

In question 1, student $C$ gives the following answer:

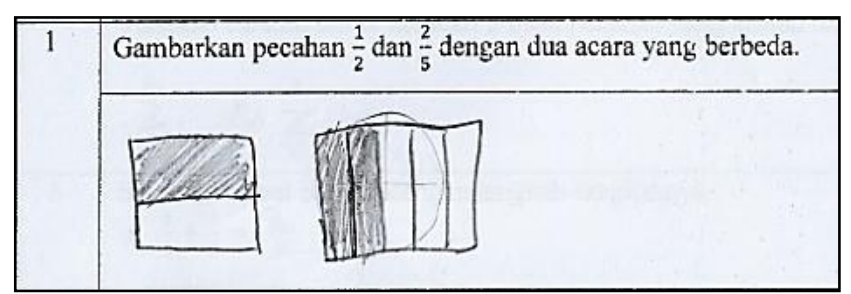

Figure 15: Student $\mathrm{C}$ answer for item \#1

In figure 15, student $C$ describes fractions $\frac{1}{2}$ and $\frac{2}{5}$ in two different ways. He draws representations of $\frac{1}{2}$ in one way, that is a rectangular image with two segments, one shaded segment, while one more segment is not shaded. At the problem $\frac{2}{5}$, he draws a representation of rectangles with five segments, with two shaded segments and the other not shaded. From the answer to question 1, it appears that he less understand fractions representation because he only draws one representation.

In question 2, student $C$ gives the following answer:

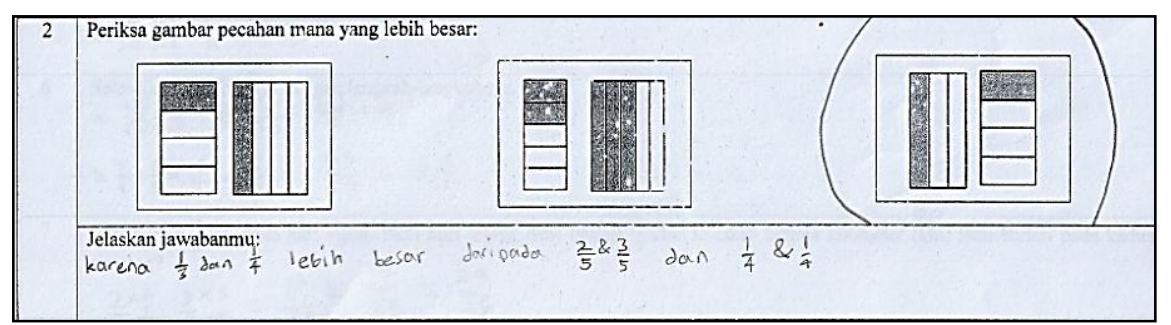

Figure 16: Student $C$ answer for item \#2

In figure 16, student $C$ checks which fractions representation images are larger. There are three different images of the problem. He writes only $\frac{1}{3}$ and $\frac{1}{4}$ larger than $\frac{2}{5}$ and $\frac{3}{5}$, and $\frac{1}{4}$ and $\frac{1}{4}$, without writing any other explanation. From the answer of number 2, it is seen that he less understand the fractions representation. 
In question 3, student $C$ give the following answers:

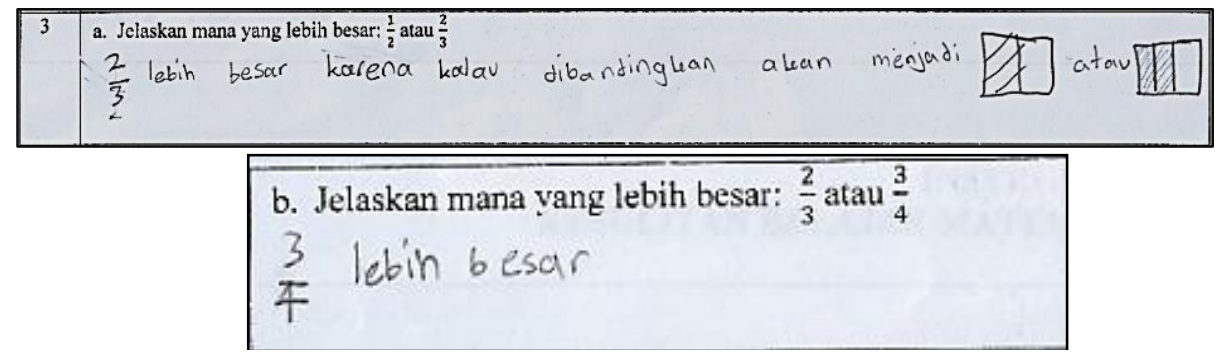

Figure 17: Student $C$ answer for item \#3

In part $a$, it is seen that student $C$ explains which fractions are larger between $\frac{1}{2}$ and $\frac{2}{3}$. He uses an image strategy to explain which fractions are larger. Fractions $\frac{2}{3}$ are depicted as three rectangular segments with two shaded segments; and $\frac{1}{2}$ represented as two rectangular segments with one shaded segment.

In part $b$, student $C$ explains which fractions are larger between $\frac{2}{3}$ and $\frac{3}{4}$. He provides the correct answer, that is $\frac{3}{4}$ is larger. However, he does not explain how the answer is obtained. From the answer of number 2, it appears that student $\mathrm{C}$ has relatively understood the fraction comparisons.

In question number 4 , student $C$ gives the following answers:

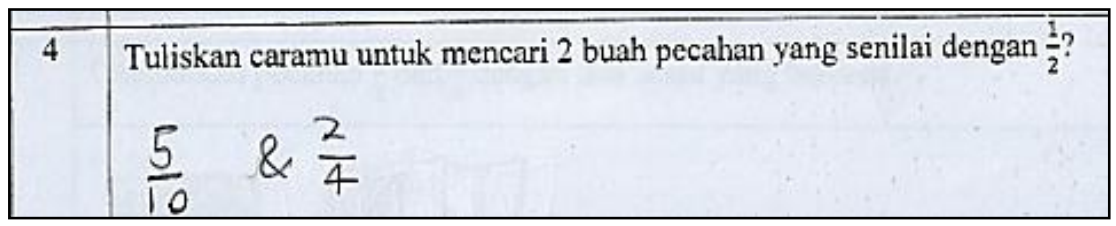

Figure 18: Student $C$ answer for item \#4

In figure 18, student $C$ writes strategies to find two fractions that equivalent to $\frac{1}{2}$. He gives the correct answers, which are $\frac{5}{10}$ and $\frac{10}{20}$. However, he does not explain how the answer is obtained. From the answer to question number 4, it appears that student $B$ has understood the topic of the fraction equivalent.

In question 5 , student $C$ gives the following answer:

\begin{tabular}{|l|l|}
\hline 5 & $\begin{array}{l}\text { Selesaikan soal berikut dengan langkah-langkahnya. } \\
\text { a. } \frac{1}{3}+\frac{1}{3}=\frac{2}{6}\end{array}$ \\
& b. $\frac{1}{3 \times 2}+\frac{1}{2} \times \frac{3}{3} \frac{2}{6}+\frac{3}{6}=\frac{5}{12}$ \\
\hline
\end{tabular}

Figure 19: Student $C$ answer for item \#5

In figure 19, student $C$ solves two questions about the addition of the fractions. In part a, he solves $\frac{1}{3}+\frac{1}{3}=\cdots$. For this problem, his answer is $\frac{1}{3}+\frac{1}{3}=\frac{2}{6}$. Student thinking can be analyzed as follows: $\frac{1}{3}+\frac{1}{3}=\frac{1+1}{3+3}=\frac{2}{6}$. 
Student $\mathrm{C}$ knows the procedure of common denominator on the fraction addition operation. So, when he sees a problem $\frac{1}{3}+\frac{1}{3}=\cdots$, he does not perform the common denominator procedure, because the denominator is the same, that is 3. Surprisingly, he adds not only the numerator but also the denominator as follows: $\frac{1}{3}+\frac{1}{3}=\frac{1+1}{3+3}=\frac{2}{6}$. He knows that the denominator of the two terms must be the same in the operation of fractions addition. However, he adds both the numerator and denominator. He mistakenly applies the procedure.

In part $b$, student $C$ solves $\frac{1}{3}+\frac{1}{2}=\cdots$. For this problem, his answer is $\frac{1}{3}+\frac{1}{2}=\frac{2}{6}+$ $\frac{3}{6}=\frac{5}{12}$. The student's way of thinking can be analyzed as follows: $\frac{1}{3}+\frac{1}{2}=\frac{(1 \times 2)}{(3 \times 2)}+$ $\frac{(1 \times 3)}{(2 \times 3)}=\frac{2}{6}+\frac{3}{6}=\frac{5}{12}$. He knows the procedure of common denominator on the fraction addition. When he sees the problem $\frac{1}{3}+\frac{1}{2}=\cdots$, he performs the common denominator strategy by changing 3 and 2 to 6 . Surprisingly, he adds not only the numerator, but he adds also the denominator, as follows: $\frac{1}{3}+\frac{1}{2}=\frac{2}{6}+\frac{3}{6}=\frac{5}{12}$. Thus, he knows the common denominator procedure on the addition operation. However, in the process, he mistakenly applies the procedure that already knew.

In question number 6 , student $C$ gives the following answer:

\begin{tabular}{|l|l|}
\hline 6 & $\begin{array}{l}\text { Selesaikan soal berikut dengan langkah-langkahnya. } \\
\text { a. } \frac{4}{8} \times 3 \frac{5}{3} \times 5 \\
\text { b. } \frac{9}{4} \div \frac{3}{5}=\frac{9}{4} \times \frac{5}{15}=\frac{60}{15}=4\end{array}$ \\
\hline
\end{tabular}

Figure 20: Student $C$ answer for item \#6

In figure 20, student $C$ solves two problems of fractions multiplication. In part a, he solves $\frac{4}{5} \times \frac{1}{3}=\cdots$. His answer is $\frac{4}{5} \times \frac{1}{3}=\frac{12}{15} \times \frac{5}{15}=\frac{60}{15}=4$. He applies the common denominator procedure to the fraction multiplication operation. When he sees a problem $\frac{4}{5} \times \frac{1}{3}=\cdots$, he performs the common denominator procedure on the first term by changing the 5 to 15 and in the second term changing 3 to 15 . Surprisingly, he only multiplies the numerator, that is $\frac{12}{15} \times \frac{5}{15}=\frac{60}{15}$. The interesting thing is that he applies the fraction addition strategy to the fraction multiplication operations.

In part $b$, student $C$ solves $\frac{9}{4} \div \frac{3}{5}=\cdots$. He gives the correct answer as follows: $\frac{9}{4} \div \frac{3}{5}=\frac{9}{4} \times \frac{5}{3}=\frac{45}{12}$. In doing this fraction division operation, he used multiplication algorithms with the reverse of the second term or invert multiply algorithm (Zembat, 2015). 
In question 7 , student $C$ gives the following answer:

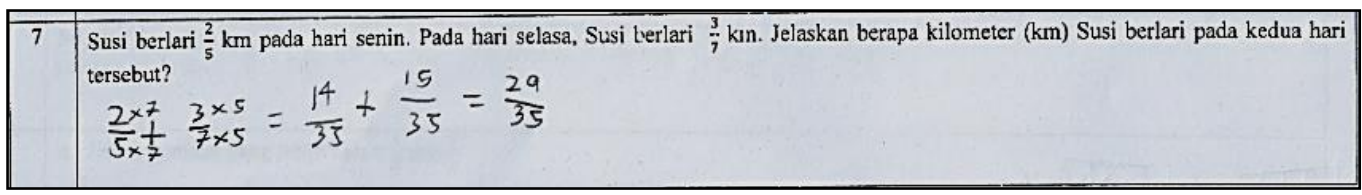

Figure 21: Student $\mathrm{C}$ answer for item \#7

In figure 21, student $C$ solves a fraction word problem. The problem is as follows: "Susi ran $\frac{2}{5} \mathrm{~km}$ on Monday. On Tuesday, Susi ran $\frac{3}{7} \mathrm{~km}$. Explain how many kilometers $(\mathrm{km})$ Susi ran on both days? ". In this case, he has been able to model the word problem into a mathematical equation, which is the fractions addition operation. Student C's answer is as follows: $\frac{2}{5}+\frac{3}{7}=\frac{(2 \times 7)}{(5 \times 7)}+\frac{(3 \times 5)}{(7 \times 5)}=\frac{14}{35}+$ $\frac{15}{35}=\frac{29}{35}$.

Student $\mathrm{C}$ knows the procedure of common denominator to the addition operation of fractions. So, once he tries to model the problem: $\frac{2}{5}+\frac{3}{7}=\cdots$, he performs the common denominator procedure by converting 5 to 35 in the first term and 7 to 35 in the second term. From the answer to question number 7, it appears that he has relatively understood the topic of the word problem of fractions.

The following table is the summary of the error pattern of student C:

Table 7: The error pattern of student $C$

\begin{tabular}{cl}
\hline No & The Error Pattern of Student $\mathbf{C}$ \\
\hline 1 & A lack of understanding of fraction representations \\
\hline 2 & $\begin{array}{l}\text { A mistake in applying the common denominator procedure to the fractions } \\
\text { addition operation, numerator and denominator are both summed up }\end{array}$ \\
\hline 3 & $\begin{array}{l}\text { Applying the common denominator procedure to fractions multiplication } \\
\text { operations }\end{array}$ \\
\hline
\end{tabular}

\section{Discussion}

From the above research findings, the three students with MLD have some similar pattern of errors. The first error pattern is students with MLD do not understand the fraction representations; this is indicated by the difficulties of the three students in answering question number 1 . The second error pattern is students with MLD do not understand the fraction comparisons. Students A and $B$ have difficulty to understand the concept of fractions comparisons; this is shown by the difficulty of student $A$ and $B$ in answering questions number 2 and 3.

The third error pattern is students with MLD are doing mistake in applying the common denominator procedure in the addition operation. Students A and B 
are doing mistake in the process when doing the common denominator procedure. They add the numerator with the same number as the denominator multiplier; when it should be multiplied. In student $C$, the common denominator has been successfully done, but in the next process, the numerator and denominator are both summed up, when it should only the numerators added together.

The fourth pattern of errors is very interesting, that is student A and C apply the common denominator procedure to the multiplication operations. While student $\mathrm{B}$ is wrong in doing the simplification of the numbers on the operation of fractions multiplication.

Four findings of the error pattern of students with MLD in understanding fractions are summarized in the following table:

Table 8: The error pattern of MLD students

\begin{tabular}{cl}
\hline No & The Error Pattern of Student with MLD \\
\hline 1 & A lack of understanding of fraction representations (All students) \\
\hline 2 & A lack of understanding of fraction comparisons (Student A and B) \\
\hline 3 & $\begin{array}{l}\text { A mistake in applying the common denominator procedure in the fraction } \\
\text { addition operation (All students) }\end{array}$ \\
\hline 4 & $\begin{array}{l}\text { A mistake in applying the procedure to the fraction multiplication operations } \\
\text { (All students) }\end{array}$ \\
\hline
\end{tabular}

In the first error pattern, the lack of understanding of fraction representations; this finding is in line with the results of Hect and Vagi (2010), Mazzocco and Devlin (2008), Piazza et al., (2010) that MLD students experience difficulty in the conceptual and representational understanding of fraction topic.

In the second error pattern, the lack of understanding of fraction comparisons, this finding is in line with the results of Butterworth and Reigosa-Crespo (2007). They state that MLD students are not able to represent abstract fractions and they have difficulty in manipulating fractions. This second error pattern is also in line with Mazzocco et al., (2011) research results that students with MLD make mistakes in comparing and estimating numbers.

In the third error pattern, which is doing a mistake in applying the common denominator procedure to the fraction addition operation; and the fourth error pattern, which is doing mistake in applying the procedure in the fraction multiplication operation; these two findings are in line with the results of Newton et al. (2014). They state that the error pattern in the fraction learning of students with MLD is the wrong application of traditional algorithms.

In the view of Brousseau (2002), the emergence of learning obstacle in mathematics can be caused by three factors, namely ontogenic obstacles (mental learning readiness), didactical obstacle (instruction from a teacher or teaching material), and epistemological obstacle (students' knowledge which has limited application context). Viewed from the Brousseau theory, the four error pattern of 
the students with MLD in this research is more inclined to the type of epistemological obstacle. The three MLD students already know fractions concept, but the application for the context of the other problems is still limited.

\section{Conclusion}

To sum up, students with MLD have a similar pattern of error when studying fraction. From the analysis of three MLD students in the inclusive school, four error patterns are found: (1) a lack of understanding of fraction representation; (2) a lack of understanding of fraction comparisons; (3) a mistake in applying the common denominator procedure in the fraction addition operation; and (4) a mistake in applying the procedure to the fraction multiplication operations.

The results of this study can be used by the teachers as a guideline when teaching fractions to students in inclusive schools. Future research is recommended to analyze the error patterns of students with other disabilities in inclusive schools, such as students with an intellectual learning disability and slow learner students.

\section{Acknowledgments}

The authors would like to thank the Indonesia Endowment Fund for Education (LPDP) as the sponsor of this research in a contract number: 20160621027192. The opinions expressed in this paper are those of the authors and do not necessarily represent the views of LPDP.

\section{References}

Bailey, D.H., Hoard, M.K., Nugent, L., Geary, D.C. (2012). Competence with fractions predicts gains in mathematics achievement. Journal of Experimental Child Psychology, 113(3), 447-455. doi:10.1016/j.jecp.2012.06.004

Brousseau, G. (2002). Theory of didactical situations in mathematics. Dordrecht: Kluwer Academic Publishers.

Butterworth, B., \& Reigosa-Crespo, V. (2007). Information processing deficits in dyscalculia. In D.B. Berch \& M. M. M. Mazzocco (Eds.), Why is math so hard for some children? The nature and origins of mathematical learning difficulties and disabilities (pp. 65-81). Baltimore, MD: Paul H. Brookes.

Castellon, L. B., Burr, L. G., \& Kitchen, R. S. (2011). English language learners' conceptual understanding of fractions: An interactive interview approach as a means to learn with understanding. In K. Téllez, J. N. Moschkovich, \& M. Civil (Eds.), Latinos/As and mathematics education: Research on learning and teaching in classrooms and communities (pp. 259-282). Charlotte, NC: Information Age Publishing.

Clarke, C., Fisher, W., Marks, R., Ross, S., Zbiek, R.S. (2010). Developing essential understanding of rational numbers for teaching mathematics in grades 3-5. Reston, VA: NCTM.

Coetzee, J., \& Mammen K.J. (2017). Science and Engineering Students' Difficulties With Fractions At Entry-Level To University. International Electronic Journal of Mathematics Education, 12(3), 281-310.

Gall, M.D., Gall, J.P., \& Borg, W.R. (2010). Applying educational research. Boston, MA: Allyn and Bacon Inc.

Geary, D.C. (2004). Mathematics and Learning Disabilities. Journal of Learning Disabilities, 37(1), 4-15. doi:10.1177/00222194040370010201 
Geary, D. C., Hoard, M. K., Byrd-Craven, J., \& DeSoto, M. C. (2004). Strategy choices in simple and complex addition: Contributions of working memory and counting knowledge for children with mathematical disability. Journal of Experimental Child Psychology, 88(2), 121-151. doi:10.1016/j.jecp.2004.03.002

Hecht, S. A., \& Vagi, K. J. (2010). Sources of group and individual differences in emerging fraction skills. Journal of Educational Psychology, 102(4), 843-859. doi:10.1037/a0019824

Hunt, J.H., Welch-Ptak, J.J., Silva, J.,M. (2016). Initial understandings of fraction concepts evidenced by students with mathematical learning disabilities and difficulties: a framework. Learning Disability Quarterly, 1(13), 1-13.

doi:10.1177/0731948716653101

Lewis, K.E. (2014). Difference not deficit: reconceptualizing mathematics learning disabilities. Journal for Research in Mathematics Education, 3(45), 351-396. doi: 10.5951/jresematheduc.45.3.0351

Lewis, K.E. (2016a). Understanding mathematical learning disabilities as developmental difference: a fine-grained analysis of one student's partitioning strategies for fractions. Journal for the Study of Education and Development, 1(21), 812-857.

doi:10.1080/02103702.2016.1215085

Lewis, K.E. (2016b). Beyond error patterns: a sociocultural view of fraction comparison errors in students with mathematical learning disabilities. Learning Disability Quarterly, 1(14), 1-14. doi:10.1177/0731948716658063

Lewis, K.E. and Fisher, M.B. (2016). Taking Stock of 40 Years of Research on Mathematical Learning Disability: Methodological Issues and Future Directions. Journal for Research in Mathematics Education, 4(47), 338-371. doi:10.5951/jresematheduc.47.4.0338

Mazzocco, M. M. M., \& Devlin, K. T. (2008). Parts and "holes": Gaps in rational number sense among children with vs. without mathematical learning disabilities. Developmental Science, 11(5), 681-691. doi: 10.1111/j.1467-7687.2008.00717.x

Mazzocco, M. M. M., Devlin, K. T., \& McKenney, S. J. (2008). Is it a fact? Timed arithmetic performance of children with mathematical learning disabilities (MLD) varies as a function of how MLD is defined. Developmental Neuropsychology, 33(3), 318-344. doi:10.1080/87565640801982403

Mazzocco, M. M. M., Feigenson, L., \& Halberda, J. (2011). Impaired acuity of the approximate number system underlies mathematical learning disability (dyscalculia). Child Development, 82(4), 1224-1237.

doi: 10.1111/j.1467-8624.2011.01608.x

Mazzocco, M,M.M., Myers, G.F., Lewis, K.E., Hanich, L.B., Murphy, M.M. (2013). Limited knowledge of fraction representations differentiates middle school students with mathematics learning disability (dyscalculia) versus low mathematics achievement. Journal of Experimental Child Psychology, 115(2), 371387. doi: 10.1016/j.jecp.2013.01.005

McKenna, J.M., Shin, M., \& Ciullo, S. (2015). Evaluating Reading and Mathematics Instruction for Students with Learning Disabilities: A Synthesis of Observation Research. Learning Disability Quarterly, 38(4), 195-207. doi:10.1177/0731948714564576

NCTM. (2000). Principles and Standards for School Mathematics. Reston, VA: National Council of Teachers of Mathematics.

Newton, K.J., Willard, C., Teufel, C. (2014). An examination of the ways that students with learning disabilities solve fraction computation problems. The Elementary School Journal, 115(1), 1-21. doi:10.1086/676949 
Piazza, M., Facoetti, A., Trussardi, A. N., Berteletti, I., Conte, S., Lucangeli, D., . . Zorzi, M. (2010). Developmental trajectory of number acuity reveals a severe impairment in developmental dyscalculia. Cognition, 116(1), 33-41. doi:10.1016/j.cognition.2010.03.012

Schifter, D. (2005). Engaging students' mathematical ideas: Implications for professional development design. Journal for Research in Mathematics Education Monograph, 13. Reston, VA: National Council of Teachers of Mathematics.

Shin, M.\&Bryant, D.P. (2016). Improving the Fraction Word Problem Solving of Students with Mathematics Learning Disabilities: Interactive Computer Application. Remedial and Special Education, 38(2), 76-86. doi:10.1177/0741932516669052

Torbeyns, J., Schneider, M., Xin, Z., Siegler, R.S. (2014). Bridging the gap: Fraction understanding is central to mathematics achievement in students from three different continents. Learning and Instruction, 37, 5-13. doi:10.1016/j.learninstruc.2014.03.002

Zembat, I.O. (2015). An Alternative Route to Teaching Fraction Division: Abstraction of Common Denominator Algorithm. International Electronic Journal of Elementary Education, 7(3), 399-422.

Retrieved from https://www.iejee.com/index.php/IEJEE/article/view/88

Zevenbergen, R., Dole, S., \& Wright, R. J. (2004). Teaching mathematics in primary schools. New South Wales: Allen \& Unwin. 